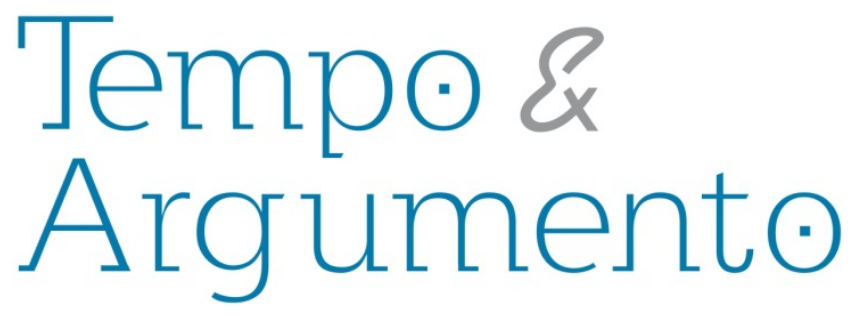

\title{
Los mapas históricos como instrumentos para la enseñanza de la historia
}

\section{Resumen}

Este artículo tiene como objetivo proponer un diálogo entre las investigaciones que analizan cómo los estudiantes comprenden los acontecimientos del pasado desde la perspectiva del pensamiento histórico y las indagaciones que, desde la historia de la cartografía, han desarrollado una mirada crítica sobre los mapas. Se considera que los mapas son instrumentos de la cultura material escolar y la reflexión crítica acerca de ellos puede aportar nuevas estrategias didácticas para la comprensión historiográfica del proceso de construcción del Estado-nación. Por otra parte, al promover un diálogo con las investigaciones sobre pensamiento histórico, se busca que los estudiantes desarrollen herramientas propias del investigador para reflexionar acerca de procesos del pasado nacional y las imágenes con que se representa al territorio. Se concluye que el campo de la enseñanza de la historia escolar se beneficiaría de los desarrollos críticos en historia de la cartografía, en tanto permiten a los estudiantes comprender no sólo lo que muestra el mapa y cómo lo muestra, sino también cómo el territorio nacional era concebido y representado en otras épocas y sociedades. En síntesis, el diálogo propuesto entre ambas disciplinas intenta promover en los estudiantes la adquisición de ciertas herramientas que les permitan historiar qué muestra el mapa y cómo lo hace.

Palabras clave: Mapas Históricos. Enseñanza de la Historia. Pensamiento Histórico. Representación del Territorio Nacional.

\author{
Cristian Abraham Parellada \\ Universidad Nacional de La Plata. Becario \\ doctoral por la Agencia Nacional de Promoción \\ Científica y Tecnológica (Argentina). \\ Buenos Aires - ARGENTINA \\ cristianparellada@hotmail.com
}

\section{Para citar este artículo: \\ PARELLADA, Cristian Abraham. Los mapas históricos como instrumentos para la enseñanza de la historia. Tempo e Argumento, Florianópolis, v. 9, n. 21, p. 312 -337, maio/ago. 2017.}




\section{Historical maps as tools for history teaching}

\begin{abstract}
This article aims to propose a dialogue between investigations that analyze how students grasp events of the past from the perspective of historical thinking and investigations that, through the history of cartography, have developed a critical look on the maps. Maps are regarded as instruments of the school material culture and critical thinking on them may provide new didactic strategies for historiographical understanding of the nation State building process. On the other hand, by promoting a dialogue with investigations on historical thinking, students are expected to develop tools inherent to a researcher to think of processes of the national past and images through which the territory is represented. It is concluded that the field of school history teaching might benefit from the critical developments in history of cartography, as they allow students to understand not only what the map shows and how it shows, but also how the national territory was conceived and represented in other times and societies. In short, the dialogue proposed between the two subjects tries to promote in students the acquisition of certain tools that allow them to historicize what the map shows and how it does this.
\end{abstract}

Keywords: Historical Maps. History Teaching. Historical Thinking. Representation of the National Territory.

\section{Os mapas históricos como instrumentos para o ensino da história}

\begin{abstract}
Este artigo tem por objetivo propor um diálogo entre as investigações que analisam como os alunos compreendem os acontecimentos do passado na perspectiva do pensamento histórico e as investigações que, a partir da história da cartografia, desenvolveram um olhar crítico sobre os mapas. Os mapas são considerados instrumentos da cultura material escolar e a reflexão crítica sobre eles pode proporcionar novas estratégias didáticas para a compreensão historiográfica do processo de construção do Estadonação. Por outro lado, ao promover um diálogo com as pesquisas sobre o pensamento histórico, espera-se que os alunos desenvolvam ferramentas próprias ao pesquisador para refletir sobre processos do passado nacional e as imagens com as quais o território é representado. Conclui-se que o campo do ensino da história escolar se beneficiaria dos desenvolvimentos críticos na história da cartografia, ao permitir que os alunos compreendam não só o que o mapa mostra e como o mostra, mas também como o território nacional era concebido e representado em outras épocas e sociedades. Em resumo, o diálogo proposto entre ambas as disciplinas procura promover nos alunos a aquisição de certas ferramentas que permitam historiar o que o mapa mostra e como o faz.
\end{abstract}

Keywords: Mapas Históricos. Ensino da História. Pensamento Histórico. Representação do Território Nacional. 


\section{Introducción}

El objetivo de este artículo es proponer un diálogo entre las teorías contemporáneas que desde la historia de la cartografía plantean una mirada crítica sobre el mapa (HARLEY, 2005; KITCHIN, DODGE, 2007) y aquellas investigaciones que, centradas en el ámbito educativo, indagan cómo se construye el conocimiento histórico en los procesos de enseñanza y aprendizaje (SEIXAS, MORTON, 2013; LÉVESQUE, 2008). Específicamente, se argumentará que promover una reflexión crítica sobre los mapas históricos puede contribuir a que los estudiantes comprendan la formación de los Estados-nación como procesos históricos.

La enseñanza de la historia en el ámbito escolar, conjuntamente con la geografía y el idioma nacional (CARRETERO, 2011), se consolidó a fines del siglo XIX y principios del siglo XX con el surgimiento de los Estados-nación. Al respecto, Hobsbawn (2012, p. 420) afirma que la necesidad “para cada 'pueblo' de un Estado totalmente independiente, territorial y lingüísticamente homogéneo" se convirtió en la versión modelo de los nacionalismos, incipientes por estos años.

A pesar de que la enseñanza escolar de la historia ha experimentado cambios durante el transcurso del siglo $\mathrm{XX}$, su objetivo didáctico al servicio de construir identidades nacionales se mantiene presente en la actualidad (FOSTER, CRAWFORD, 2006; NAKOU, BARCA, 2010). Una herramienta indispensable para la enseñanza de la historia son los libros de texto escolares, los cuales tienen como característica común, aunque en diferentes grados, ser nacionalistas, y contribuir a reforzar las identidades nacionales, ideológicamente construidas (FOSTER, 2012). Efectivamente, las historias nacionales han sido diseñadas para ser enseñadas (CARRETERO, 2011).

Los libros de texto son una herramienta indispensable en el aula, a través del estilo narrativo oficial que predomina en la mayoría de ellos, se refuerza la idea de un pasado común compartido por los miembros de un Estado-nación (FOSTER, 2012). En este sentido, se puede sostener que las narrativas históricas vigentes en muchos manuales escolares transmiten ciertas visiones del pasado que enfatizan la unidad y el orgullo nacional con el fin de promover la unidad nacional (FOSTER, 2012). Así, por ejemplo, 
Por otra parte, los mapas son un recurso que se encuentra presente en la mayoría de los manuales y, muchas veces, sirven a los fines de ilustrar la información contenida en los relatos históricos. Los procesos acontecieron en un determinado territorio y dicho territorio es 'imaginado' por los ciudadanos y las instituciones como parte de una determinada nación (ANDERSON, 1983), los mapas son los instrumentos a través de los cuales se materializa tal imaginación territorial. En este punto, es conveniente recordar que el territorio nacional no es inmutable, por el contrario, a partir de determinados acontecimientos históricos, puede sufrir cambios en el proceso de constitución de la propia nación. Por ejemplo, en el caso de Argentina el territorio que se independizó y el actual son radicalmente distintos (ENTIN, 2016).

En los contenidos de los manuales escolares de historia, en muchas ocasiones, lo territorial muchas veces es entendido como una categoría estática, atemporal, neutral y apolítica; es decir, como un escenario pasivo sobre el cual los sujetos históricos juegan sus respectivos roles. En lo que sigue, se expondrán algunas reflexiones que se han desarrollado al interior de la historia de la cartografía y que promueven una mirada diferente sobre los mapas. Luego, estas premisas serán puestas en diálogo con investigaciones que desde una perspectiva centrada en el ámbito educativo abordan el problema de cómo los estudiantes construyen el conocimiento histórico. Se considera que, para favorecer el desarrollo del pensamiento crítico acerca de los procesos de formación de los Estados-nación, es necesario que los estudiantes indaguen a los mapas históricos con herramientas propias de la historia y de la cartografía.

\section{Investigaciones en la historia de la cartografía}

Los mapas son uno de los métodos privilegiados a través de los cuales la geografía ha representado el espacio. Esta disciplina, según una definición clásica (ROBINSON, 1952), se encarga de la descripción gráfica de la tierra y los mapas son el instrumento por 

territorio y de sus cambios, casi como un espejo de la realidad (ROBINSON, 1952).

Por otra parte, en los últimos años, una nueva perspectiva de investigación, que surge específicamente en el área de la historia de la cartografía, sugiere que es preciso complejizar la mirada clásica sobre los mapas con la comprensión del modo en que funcionan al interior de una sociedad. Desde esta perspectiva, Lois (2014) aplicó una mirada historiográfica sobre los mapas y argumentó que los significados de estos dependen del entrecruzamiento de contextos políticos e institucionales que los promueven. Lo que se propone es que son las situaciones sociales las que actualizan y reactualizan las miradas sobre los mapas, otorgándoles legibilidad. En otras palabras, este enfoque destaca el análisis historiográfico de los contextos de producción y consumo, porque "es en el juego social donde los mapas cobran existencia material, sensorial, sentidos y valores" (KANTOR, 2014, p. 12).

En palabras de Ramaswamy (2001), los ciudadanos visualizan el tamaño, la extensión y los contornos del territorio de la nación a través del mapa. De esta manera, el mapa es una herramienta necesaria mediante la cual se espera que los ciudadanos de un Estado-nación desarrollen un sentimiento afectivo hacia el territorio nacional. Si no fuera por el mapa, que les permite a los ciudadanos materializar visualmente cómo y dónde están espacialmente ubicados, el espacio-nación seguiría siendo una entidad abstracta. Es muy probable que sea ésta la razón por la que en cada escuela, pública o privada, de la mayoría de los países siempre ha habido un mapa del Estado-nación presente en el aula.

Desde una perspectiva historiográfica, Anderson (1983) sostiene que el mapa, junto con el museo y el censo, constituye una pieza clave para reflexionar sobre el proceso de invención de una nación, en tanto favorece la integración nacional y el desarrollo de un sentimiento patriótico. El contorno que muestra un mapa permite percibir como propio todo lo que acontece dentro de sus límites y como ajeno lo que sucede fuera (HERZOG, 2017). De esta manera, no resulta extraño que el objetivo de múltiples investigaciones haya sido mostrar como los mapas contribuyeron a la 
Además, todas las sociedades necesitan sentirse arraigadas a un territorio, lo que les proporciona seguridad y afianza su sentimiento de pertenencia (HOBSBAWN, 1998; ORRIDGE, WILLIAMS, 1982; VILAR, 1982). Así, los argumentos territoriales son claves para definir la soberanía estatal y delimitar el espacio sobre el cual el Estado ejerce la misma (NOGUÉ, 1998). De allí la preocupación de los gobernantes por afianzar un tipo de conocimiento disciplinar que permita establecer precisos límites fronterizos y que contribuya a consolidar la conciencia nacional (HERZOG, 2017). En este sentido, en los últimos años ha proliferado un conjunto de investigaciones que destacan el rol que la geografía escolar y que las representaciones territoriales tienen en la construcción y el modelamiento de la conciencia nacional (KAPLAN, HERB, 2011).

Las investigaciones que han indagado los vínculos entre geografía y construcción del sentimiento de nacionalidad han sido variadas y, aunque con diferencias teóricas, casi todas muestran sólidamente que los conocimientos propios del campo de la geografía y las representaciones del espacio elaboradas contribuyeron a la formación de identidades nacionales en varios países del mundo (DEL CASTILLO, 2011; HERB, 1997; KOSONEN, 2008; LEUENBERGER, SCHNELL, 2010; LOIS, 2014).

Dentro de las instituciones escolares, las propuestas curriculares de historia y geografía han garantizado tal empresa y el mapa es un elemento común presente en ambas disciplinas (OFFEN, DYM, 2011). Como sostuvo Gramsci (1971), los movimientos nacionales y los Estados-nación siempre han utilizado a los mapas para fortalecer imágenes y narrativas sobre la nación. De esta manera, las técnicas de inclusión u omisión de cierta información visual y lingüística, tales como reducir o exagerar algunos elementos visuales y seleccionar determinados símbolos y escalas, en detrimento de otros, son herramientas con las que el cartógrafo cuenta al momento de realizar un mapa. Así, el diseño de los mapas puede representar las fronteras nacionales preferidas ante un caso de conflicto o reclamo territorial, enfatizar las potenciales amenazas de países limítrofes, estimular la adhesión o el rechazo de los miembros de una comunidad a 
Es pertinente recordar que los mapas, como cualquier artefacto cultural, son una construcción social (CRAMPTON, 2001) y, a través de ellos, se visibilizan algunas cosas y se ocultan otras, según los intereses y los conocimientos de quienes los encargan y quienes los producen. De esta manera, los mapas no son ingenuos y, mediante ellos, se promueven visiones y representaciones sobre un lugar o una sociedad. Por ende, los mapas, en tanto instrumentos que no son independientes de los contextos políticos y sociales en los que son producidos, brindan elementos sobre las representaciones que una sociedad tiene del espacio y el lugar. $\mathrm{Y}$, por medio del análisis de ellos, se puede acceder a información acerca de las prácticas sociales de consumo y reapropiación mediante las cuales las representaciones cartográficas adquieren significado.

En síntesis, las consideraciones esgrimidas hasta aquí favorecieron el desarrollo de un conjunto de investigaciones promovidas al interior de la historia de la cartografía que cuestionaron a la visión del mapa como representación neutra del espacio. Es esta perspectiva crítica, la que puede ser considerada por investigaciones sobre enseñanza escolar de la historia, porque interroga a los mitos territoriales que se legitiman a partir de concepciones técnicas y objetivas de las representaciones del territorio.

\section{El mapa como documento de la cultura material escolar}

Los desarrollos comentados hasta el momento, propios del ámbito de la historia de la cartografía, pueden ser considerados para reflexionar acerca de cómo los mapas escolares, en tanto instrumentos diseñados para la enseñanza, se entraman en el conjunto de relaciones culturales más amplias en las que cobran significado.

El mapa, en tanto artefacto didáctico presente en las aulas y en los manuales escolares, constituye un elemento clave de la cultura material escolar (SOUZA, 2007). Es preciso considerar que los mapas en tanto artefactos culturales 
[...] son productos del trabajo humano y presentan dos facetas: por un lado, tienen una función primaria (una utilidad práctica) y, por otro lado, ejercen funciones secundarias, esto es, simbólicas. Hay que considerar que los artefactos son indicadores de las relaciones sociales y como parte de la cultural material actúan como rectores y mediadores de las actividades humanas, lo que les confiere a los objetos un significado (SOUZA, 2007, p. 169, nuestra traducción).

La propuesta habilita un diálogo no sólo con las investigaciones preocupadas en indagar qué factores son los que intervienen en la producción de un mapa, sino también con aquellas investigaciones que buscan dar respuesta a las apropiaciones y los usos de estos materiales por los agentes escolares. En la medida en que los mapas son analizados críticamente en el aula, pueden promover el desarrollo de nuevas estrategias educativas.

Desde esta perspectiva, puede asumirse que, en el ámbito escolar, el conocimiento geográfico promueve categorías espaciales (e.g. fronteras, territorio) y las mismas se expresan mediante imágenes, mapas y narrativas escritas y habladas, entre otras construcciones culturales que forman parte de la cultura material escolar. Además, como sostienen algunos autores de la cartografía crítica, los mapas tienen y cuentan una historia (Edney, 1997, Wood, 2010). Es en este sentido que los mapas pueden ser considerados como artefactos culturales y, a su vez, se constituyen en parte importante de la cultura material escolar.

La reflexión sobre los mapas, como elementos de la cultura material escolar, puede motorizar un análisis crítico de que concepción de territorio es la que predomina en el escenario escolar. Al hablar de territorio, no se refiere simplemente un escenario con ciertas características específicas. Más bien, el término denota algo mucho más complejo. Por ejemplo, la referencia a un territorio puede entramar es sí mismo el relato acerca de cómo ese territorio se fue organizando políticamente y cómo se llevaron a cabo las batallas políticas y militares que le dieron forma. En otras palabras, el uso de mapas históricos contribuye también a poner de relieve los acontecimientos históricos que están relacionados con las disputas de los diferentes grupos sociales en diferentes partes del mundo. Este enfoque es de interés porque, si la educación histórica descuidara las diversas connotaciones del término territorio, los estudiantes y los ciudadanos podrían obtener la impresión errónea de que los territorios actuales y sus unidades políticas no han cambiado a través del tiempo. 


\section{Investigaciones en enseñanza y aprendizaje de la historia}

Los miembros de un Estado-nación comparten y reconstruyen complejos relatos acerca de la historia nacional, de su pasado como grupo y como sujetos miembros de una comunidad. Seixas y Morton (2013, p. 1 , nuestra traducción), al reflexionar sobre los fines de la enseñanza, sostienen que todos los objetos del mundo actual "fueron diseñados, fabricados, vendidos, transportados y colocados en su lugar actual en el pasado -su existencia hoy es por lo tanto una extensión del pasado". Al partir de este supuesto, la enseñanza de la historia escolar tiene por objetivo brindar a los estudiantes herramientas de pensamiento que les permitan problematizar qué aspectos del pasado se encuentran en los objetos del presente, para transformar el mundo actual. El concepto de pensamiento histórico (historical thinking) se encuentra en los trabajos de muchos investigadores que trataron de dar respuesta a tal objetivo (DOMINGUEZ, 2015; GÓMEZ CARRASCO, 2014; LEE, 2005; LÉVESQUE, 2011; SEIXAS, MORTON, 2013), y surgió en contraposición al discurso histórico descriptivo y acrítico. Para los autores que adhieren a la perspectiva teórica del pensamiento histórico, saber historia implica el manejo de ciertas habilidades de razonamiento, análisis e interpretación de datos, propias de esta disciplina, que deben aprenderse (WINEBURG, 2001).

Como anteriormente se mencionó, el objetivo de construir y afianzar identidades sociales, culturales y políticas mediante una enseñanza tradicional de la historia está aún presente en las escuelas (CARRETERO, 2011). Sin embargo, frente a este enfoque en las últimas dos décadas, los grupos de investigación más innovadores están apostando por la perspectiva del pensamiento histórico y el conocimiento sobre historia (BARTON, 2008; CARRETERO, LEE, 2014; GÓMEZ CARRASCO, 2014; SEIXAS, MORTON, 2013). En estas investigaciones, es común distinguir dos tipos de contenidos históricos. Por un lado, los contenidos que intentan responder a interrogantes del pasado a través de las preguntas ¿Qué? ¿Quién? ¿Cuándo? y ¿Dónde? y, por otro lado los contenidos que suelen llamarse conceptos de segundo orden o metahistóricos.

Los contenidos de segundo orden hacen referencia al desarrollo de ciertas estrategias que permiten a los sujetos acercarse al conocimiento del pasado con instrumentos de análisis historiográfico. Las mismas se concretizan en la utilización de 

(LÉVESQUE, 2008; SEIXAS Y MORTON, 2013). En otras palabras, los contenidos metahistóricos, o de segundo orden, suponen la implementación, por parte del sujeto, de ciertas habilidades que permiten abordar los procesos del pasado como un historiador y entender de una forma más compleja el pasado (BARTON, 2008; LEE, 2005; VANSLEDRIGHT, 2014; VANSLEDRIGHT, LIMÓN, 2006).

Sin embargo, se observa que si bien en todas las investigaciones comentadas las referencias a argumentos territoriales y espaciales están implícitas, ninguna reflexiona específicamente sobre la importancia de trabajar con mapas históricos como herramienta indispensable para la enseñanza de la historia escolar.

\section{Historia de la cartografía y pensamiento histórico}

El objetivo que se propone en este trabajo puede ser considerado conjuntamente con lo planteado por Peck y Seixas (2008). Los autores, diferencian tres maneras generales en las que se suele concebir la educación histórica en el espacio escolar: 1) centrada en la narrativa de la construcción de la nación; 2) a través del análisis de problemas contemporáneos en un contexto histórico; y 3) centrada en promover en los estudiantes una comprensión de la historia como un método, como una manera de investigar $\mathrm{y}$, por lo tanto, aprender a pensar y reflexionar históricamente. Gómez Carrasco (2014) sostiene que estos tres enfoques para la enseñanza de la historia escolar no son necesariamente incompatibles entre sí. Al igual que el mencionado autor, se considera a los fines de este trabajo que es pertinente disponer de un enfoque que esté en consonancia con la tercer propuesta, para favorecer el desarrollo del pensamiento histórico y promover una comprensión crítica de los acontecimientos del pasado.

Es preciso recordar que la capacidad de reflexionar y plantear problemas históricos son habilidades que se aprenden y que, por tanto, han de explicitarse en la enseñanza (ARTEAGA, CAMARGO, 2014; BARTON, LEVSTIK, 2008; VANSLEDRIGHT, 2014). En este artículo se sostiene la idea de que el trabajo con mapas históricos contribuye al 
historia y el trabajo con mapas históricos exige la comprensión de la naturaleza propia de la disciplina y de la actitud propia del investigador que reflexiona no sólo sobre el pasado, sino también sobre la imagen que lo representa. En palabras de Lois (2014, p. 88), "Ios mapas parecen animarse cuando sus formas y 'cuestión visual' son reinstaladas en la red de instituciones, saberes, prácticas, tradiciones, políticas educativas, sentido común geográfico, sentimientos nacionales, estrategias geopolíticas que los hacen comprensibles para una sociedad". Es precisamente esta consideración la que permite movilizar una serie de habilidades que están presentes en el momento de plantear problemas históricos, mediante el análisis y la obtención de evidencias a partir de fuentes y pruebas históricas. En otras palabras, se insiste en la necesidad de enfocar un aprendizaje de la historia centrado en la investigación, la indagación y en métodos basados en problemas, para que los alumnos desarrollen complejas habilidades cognitivas que les permitan comprender y explicar los fenómenos históricos. En este caso, promover la historización del territorio y la mirada crítica sobre las representaciones cartográficas. Lo que se propone es permitir al estudiante considerar al mapa como una fuente y un instrumento de análisis histórico en sí mismo y brindarle herramientas para ir más allá de la mera percepción directa de lo que el mapa muestra. Sin estas herramientas, para desarrollar cualquier análisis crítico se hace difícil superar la cristalización del mapa como una imagen esencialista y atemporal que refuerza los mitos territoriales (CAIRO CAROU, 2000).

En la actualidad, no se trata de reflexionar acerca de si el mapa es una imagen técnica o política, sino que un debate actual al interior de las investigaciones en la historia de la cartografía es el de la relación entre el mapa y el objeto que representa (LOIS, 2014). Desde esta perspectiva, no se trata de sustituir una representación espacial por otra, porque se corre el riesgo de volver a seducir la mirada con otro mapa que "adula el ego nacionalista de verse en el centro del mundo, pero que empobrece la reflexión sobre la relación entre territorio, cartografía, poder y formas de ejercer el poder" (HOLLMAN, LOIS, 2015, p. 125). 
Cada representación cartográfica de un territorio está compuesta de elementos que permiten explicar las continuidades y cambios del cuerpo del Estado-nación. La enseñanza de las transformaciones territoriales de la nación debe hacerse teniendo presente estas relaciones. Es preciso considerar que los mapas son los instrumentos por los cuáles los estudiantes acceden a la comprensión de los cambios que se dieron en el territorio de un Estado-nación, como producto de procesos históricos. Lo mismo puede decirse de la enseñanza del tiempo histórico (PAGÈS BLANCH, SANTISTEBAN FERNÁNDEZ, 2010). En este sentido, se torna necesario que el elemento cronológico esté siempre presente y explícitamente definido. Por ejemplo, al observar el mapa de la Ilustración 1, el estudiante tiene que considerar elementos presentes en la misma imagen que refieren a representaciones cronológicas y espaciales distintas, sin estar debidamente explicitadas.

\section{Ilustración 1}

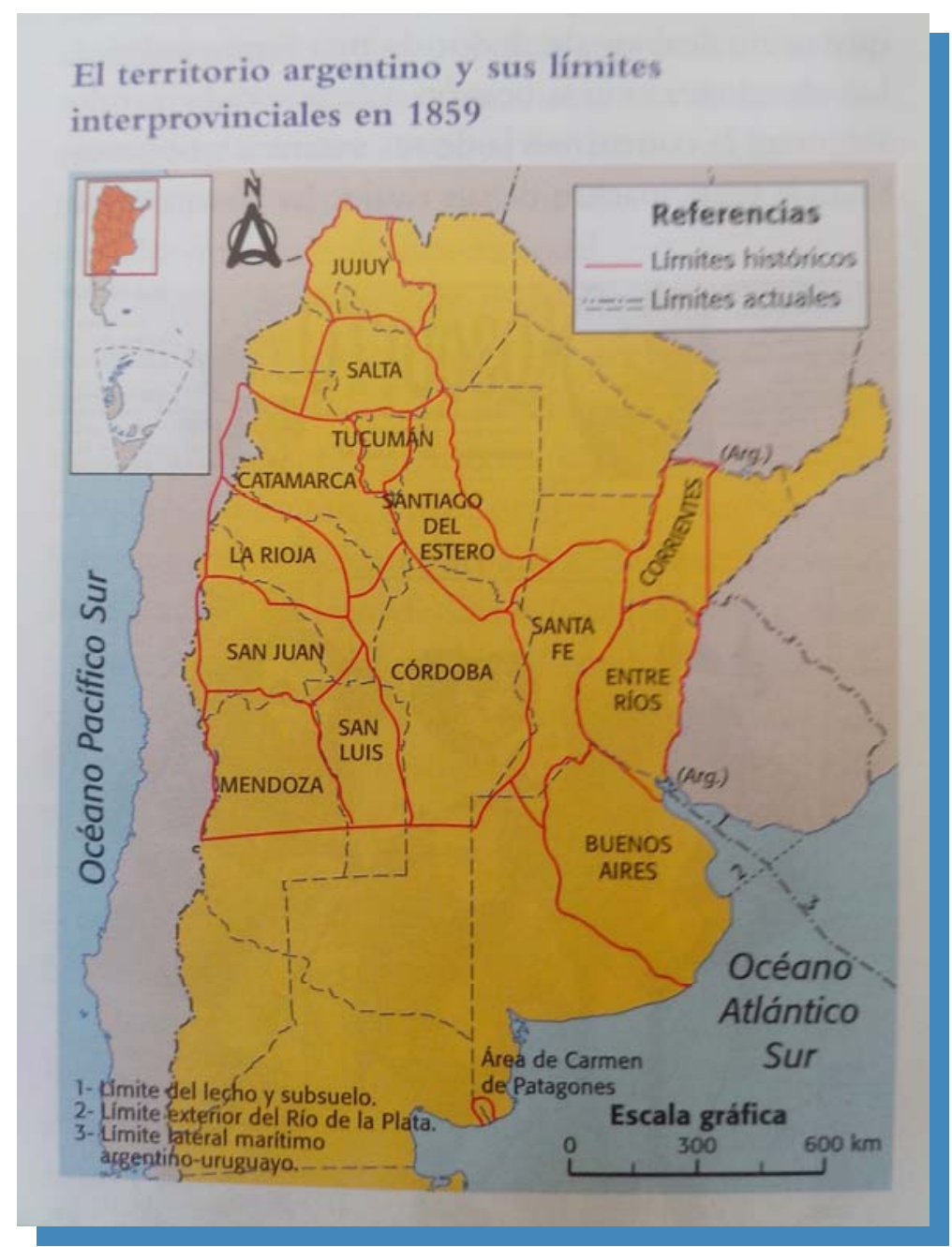


La imagen arriba ilustrada corresponde a un manual de enseñanza de la Escuela Secundaria de la Provincia de Buenos Aires (PÉREZ et al., 2013) y hace referencia a la Confederación Argentina en 1859. Por estos años, el Estado argentino estaba en formación y los límites lejos estaban de ser similares a los actuales (CHIARAMONTE, 2004; OSZLAK, 2012). El 31 de mayo de 1852 se celebró el Pacto de San Nicolás de los Arroyos, el mismo fue ratificado por 13 provincias, entre las que no se encontraba Buenos Aires. El acuerdo establecía entre sus artículos que era momento de constituir un Congreso General Federativo, para ejercer la administración general del País, bajo un sistema federal. Además, de proponer la federalización del cobro y distribución de rentas, el pago de la deuda de la república y la distribución de las rentas generales, entre otros aspectos (GARAVAGLIA, 2015). Sin embargo, la legislatura de Buenos Aires rechazó el acuerdo y durante casi una década Buenos Aires y la Confederación se enfrentaron, lo que generó una situación muy inestable en el que ambas entidades competían y se atacaban militarmente - y se diferenciaban desde el punto de vista cultural, económico y social.

Al mirar detenidamente a la imagen anterior, se observan unos trazos rojos identificados con la leyenda límites históricos y en líneas punteadas se representan los trazos de los límites actuales. Acerca de este último punto, es pertinente reconocer que una primer mirada sobre la imagen muestra que, como base para la representación territorial, se utiliza un mapa actual en el que se encuentran presentes los límites internacionales claramente definidos. Los territorios que conforman a la Argentina actual, pero que en estos años no formaban parte del control efectivo del Estado, están coloreados del mismo tono que los pertenecientes a la Confederación Argentina. A su vez, el territorio que por estos años formaban parte de la Confederación Argentina, pero actualmente se encuentra bajo dominio efectivo de otros Estados, está coloreado en otra tonalidad cromática. Por otra parte, en la parte inferior de la imagen aparecen actividades, relacionadas con el contenido del relato, que no guardan ninguna relación con el mapa. Por ejemplo, se les pide a los estudiantes que enumeren las causas de la secesión de Buenos Aires y que expliquen las distintas posiciones políticas que existieron durante estos años. 
Además, como puede apreciarse, la imagen no es una representación cartográfica de la época. De esta manera, no cumple la función de ser una fuente histórica, ni desde las actividades comentadas, en relación con la imagen, se promueve en los estudiantes una reflexión crítica del mapa que están observando. Hay una escisión entre el mapa y las actividades, por un lado, se presentan la imagen y, por otro lado, las actividades propuestas están relacionadas con contenidos del texto. Este tipo de relación entre actividad y texto puede ser considerado bajo la óptica clásica de lo que un mapa representa (DAVIS, 1968): según la cual el mapa funciona como un espejo que sintetiza y refuerza la información más relevante de lo que se describe en el texto, pero no cómo un elemento a ser abordado críticamente.

Como se ha señalado, desde la perspectiva clásica, y más difundida al interior de las escuelas, que conforma el sentido común visual (HOLLMAN Y LOIS, 2015) se defiende la idea de que el mapa es una representación de la tierra basada en procedimientos matemáticos y geométricos y, como tal, refleja la realidad como es o como fue. Así, el mapa ilustrado si no se problematiza se constituye en una fotografía instantánea, fija y permanente, un momento de una porción de la tierra.

Es pertinente hacer la salvedad que la imagen ilustrada no representa un ejemplo oportunista. Por el contrario, es un caso paradigmático de cómo la mayoría de los manuales escolares y diseños curriculares actuales ilustran las transformaciones territoriales históricas, en Argentina y en otros países (HERZOG, 2017; KAMUSELLA, 2010; PARELLADA, 2016; QUINTERO, 1999). Además, en Argentina, el actual Instituto Geográfico Nacional, dependiente del Ministerio de Defensa de la Nación, es el organismo oficial que regula las publicaciones referidas a representaciones cartográficas nacionales. Es decir, toda representación total o parcial del territorio nacional que se reproduzca en distintos medios, incluidos los manuales escolares, debe contar con el aval de este organismo. Detrás de este intento por regular la imagen cartográfica es posible encontrar nuevamente la hipótesis, ya comentada, de que los mapas inciden en los modos en que los miembros de un Estado ven y entienden el territorio nacional, en el presente y en el pasado. 
Este análisis se hace eco de las palabras de Lois (2014, p. 109), quien sostiene que “el enfoque autocentrado en una nación ha servido para recortar hechos históricos tomando la nación presente como plantilla retrospectiva". En consonancia con la imagen esencialista, las narrativas también están autocentradas en el Estado-nación - los territorios que no corresponden a la Argentina actual no son coloreados - lo que clausura la posibilidad de comprender los procesos en el contexto regional en el que se producen "y de los cuales no deberían ser escindidos a riesgo de sacrificar elementos explicativos" (LOIS, 2014, p. 110). Por lo tanto, se omite que lo representado es algo que cambia en el tiempo como producto de las acciones de las personas.

En este punto, la representación cartográfica es solidaria del objetivo de construcción de ciudadanos nacionales ya que se transmite un mapa-logotipo (ANDERSON, 1983), emblemático de la nación, sobre la base de considerar un territorio nacional imaginado, con características esencialistas, es decir que nunca existió de otra manera. En el caso de Argentina, la construcción de la identidad nacional, como se ha mencionado, ha tomado a la historia territorial como un elemento central de las narrativas (CAVALERI, 2004). Las narrativas históricas del discurso escolar (ROMERO, 2004) junto a la repetición de una imagen cartográfica estándar contribuye a naturalizar el mapa, de esta manera el mismo es la trascripción técnica del territorio real del Estado.

En esta lógica nacionalizante, los mapas que no se ajustan al imaginario territorial de los Estados-nación tienden a ser excluidos, no sólo de las revisiones cartográficas nacionalistas, sino también de los instrumentos sobre los que se busca formar ciudadanos de un Estado-nación. Tal el caso de mapas como el de Martín de Moussy (1865) (ver Ilustración 2) y el de Marbais du Graty (1858) (ver Ilustración 3). Específicamente, llama la atención que ambos mapas estén disponibles en el portal web del Ministerio de Educación Nacional, como recurso didáctico, pero no estén presentes en los libros de texto escolares. Además, con respecto al mapa de de Moussy (1865), es por lo menos curioso que se encuentre ausente de todos manuales escolares, ya que el mismo fue considerado el documento cartográfico oficial de la Confederación Argentina hasta fines del siglo XIX (LOIS, 2012), momento en el cual el Estado nacional emprendió una fuerte campaña expansionista sobre los territorios del sur. 


\section{Ilustración 2}

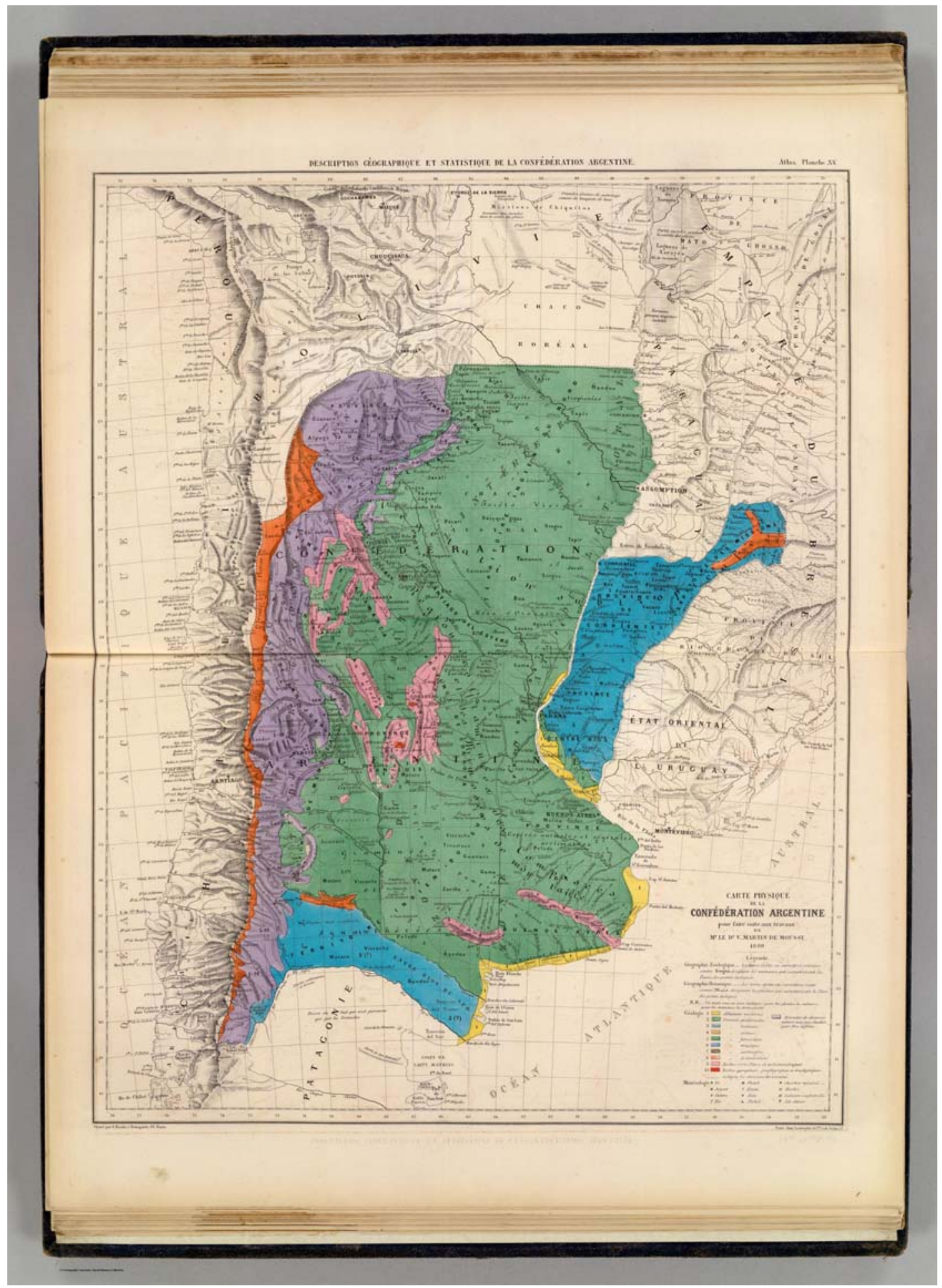

Fuente: https://imagenes.educ.ar/repositorio/imagen/ver?image_id=42d48c70-078d-4cc7-b34bf7ff2of6ad56 
Ilustración 3

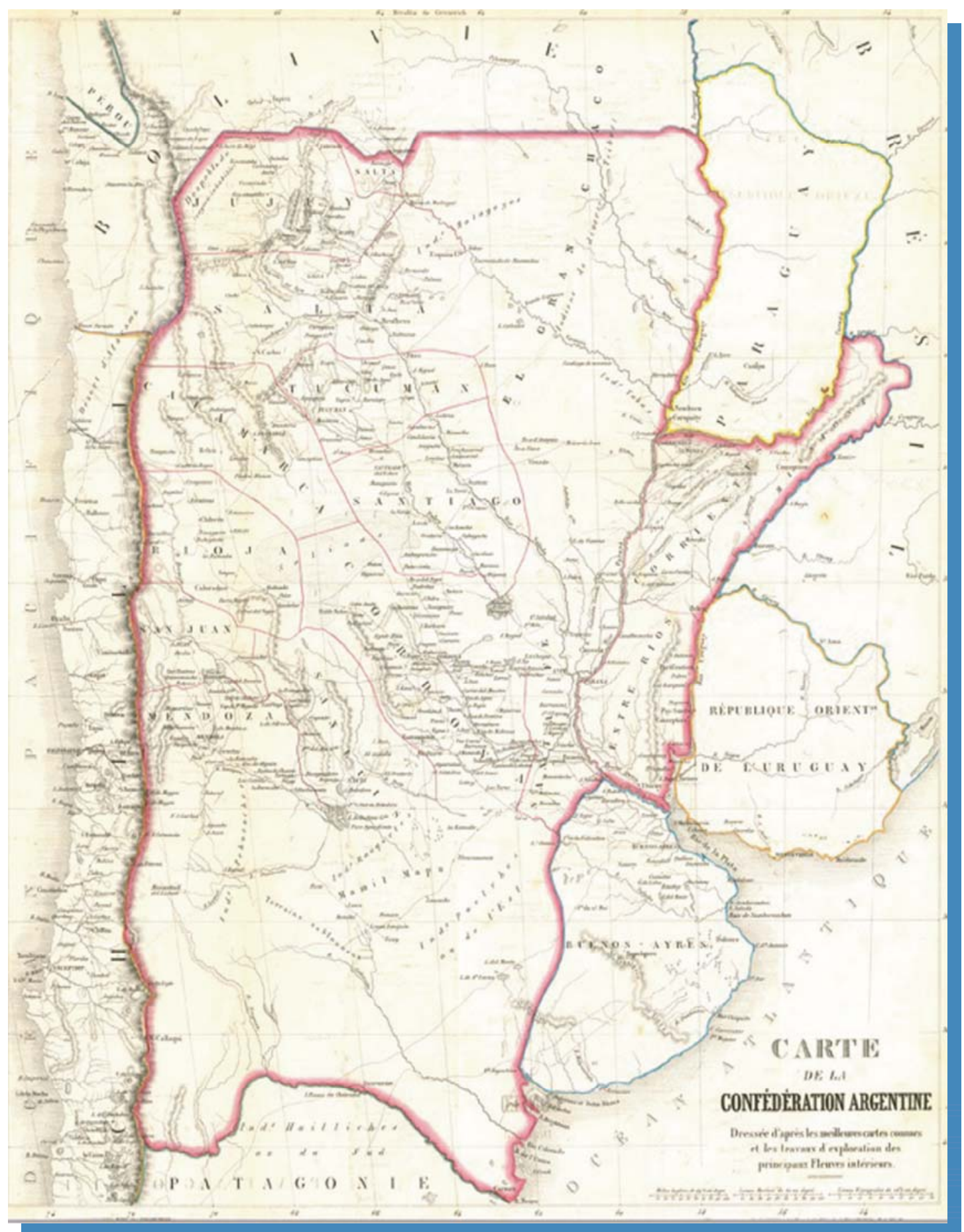

Fuente:https://imagenes.educ.ar/repositorio/imagen/ver?image_id=55cf6619-ccd6-4069-83cod621231bf332 
Cabe aclarar que lo que se propone no es la mera inclusión de estas últimas imágenes en los manuales escolares. Ya que exponer a los estudiantes a una nueva representación gráfica sin analizarla críticamente obturaría el desarrollo de las estrategias de pensamiento de segundo orden. Pero, se considera que reflexionar sobre la imagen cartográfica y compararla con un mapa actual del Estado nacional puede convertirse en un instrumento indispensable para que los estudiantes se acerquen al pensamiento histórico para comprender los procesos de formación del Estado-nación. Es decir, lo que se propone es el trabajo crítico en el aula con mapas históricos, para que los estudiantes desarrollen estrategias de análisis de la representación del territorio y no los vean como representaciones esencialistas y naturalizadas de la demarcación territorial de un Estadonación.

Desde esta propuesta, los contenidos a trabajar en el aula además de la información conceptual y factual (hechos, conceptos, datos) deberían estimular en los estudiantes la capacidad argumentativa y de razonamiento, o lo que algunos autores denominan que el alumnado aprenda a razonar y pensar históricamente (CARRETERO, 2012; GÓMEZ CARRASCO, ORTUÑO, MOLINA, 2014; LÓPEZ FACAL, 2000; VALLS, 2008), tanto con el contenido del texto como con los mapas.

\section{Conclusión}

A lo largo del artículo, se ha propuesto reflexionar sobre la importancia los mapas históricos al momento de enseñar historia, ya que los acontecimientos del pasado ocurren en un espacio que tienen las características de ser dinámico e históricamente construido. En este sentido, se han habilitado las posibilidades de considerar como se pueden beneficiar las propuestas que tienen como objetivo dotar a la enseñanza de la historia de una metodología que promueva en los estudiantes el desarrollo de un espíritu crítico y la utilización de herramientas disciplinares si consideran algunos aportes de las investigaciones actuales en la historia de la cartografía.

En este punto, es posible considerar que las investigaciones en la historia de la cartografía pueden aportar al campo de la enseñanza de la historia escolar, un conjunto 

sociedades un espacio. La propuesta no se limita a reconocer solamente que a través de lo que muestran y ocultan los mapas se activan y reproducen ciertas relaciones de poder, sino también a promover en los estudiantes el uso de herramientas historiográficas que les permitan historiar qué muestra el mapa y cómo lo hace. Además, un análisis reflexivo sobre el mapa histórico se constituye en una herramienta necesaria para que los estudiantes se acerquen al pensamiento histórico en los procesos de formación del Estado-nación. Es decir, lo que se propone es el trabajo en el aula con mapas históricos que posibiliten el desarrollo de una perspectiva histórica sobre la representación del territorio y no representaciones esencialistas y naturalizadas de la demarcación territorial de un Estado-nación.

A lo largo de lo planteado en este artículo, puede considerarse que es posible pensar una interacción entre la enseñanza escolar de la historia y los nuevos planteos teóricos desarrollados en la historia de la cartografía. No cabe duda de que hay una serie de elementos que habilitan el desarrollo de una mirada sobre el mapa que son constituyentes del pensamiento histórico, a saber: la capacidad de plantear problemas históricos en base a su relevancia e impacto en las sociedades y el uso crítico de los mapas como fuentes.

Los desarrollos considerados en la historia de la cartografía entienden a los mapas como representaciones gráficas que pueden ser analizadas y permiten comprender no sólo los pueblos, espacios y épocas que retratan, sino también las sociedades en las que fueron creados y consumidos. Desde este punto de partida, es posible entender que los mapas históricos constituyen una excelente fuente de análisis para que los estudiantes interroguen cómo se definen, miden, organizan, ocupan, resuelven, comprenden y discuten los espacios que ocupan los Estados nacionales (OFFEN, DYM, 2011). Es decir, permiten entender que los Estados-nación son un producto histórico. De esta manera, los mapas pueden dar a los estudiantes acceso a una gran variedad de conocimientos de segundo orden y al desarrollo de estrategias de pensamiento crítico, si se promueve el 
reflejan la realidad. Presentar al mapa como mero instrumento que acompaña un relato histórico impide la problematización de la representación y los muestra como objetos transparentes, cuya función es dar información técnica sobre lo que la realidad fue o es. Sin embargo, al problematizarlos y favorecer que los estudiantes los indaguen analíticamente como a otras fuentes más tradicionales del conocimiento histórico, los mapas pueden mejorar la comprensión y la enseñanza de la historia escolar del Estadonación en relación con el contexto regional (e internacional) del que es inseparable.

Por último, al entender a los mapas como herramientas que desempeñan un papel fundamental en la generación de narrativas históricas y que contribuyen al desarrollo de un conocimiento territorial, del presente y del pasado imaginado, es posible aproximarse a los contextos sociales y políticos que favorecieron su producción y consumo. Anderson (1983), al describir a la nación como una comunidad política, sostiene que en los miembros de una comunidad tienen una representación imaginada del territorio que dicha nación ocupa. Pero dicha imagen no sólo actúa en el tiempo presente, también como se ha argumentado es transmitida al pasado imaginado de la comunidad como plantilla para comprenderlo. El mapa es utilizado por los gobiernos como una herramienta que contribuye al establecimiento de una imagen acrítica y atemporal del territorio (ANDERSON, 1983), de allí la importancia de abordarlo históricamente en el ámbito escolar.

En otras palabras, lo que se sugiere es que mientras se sigan imponiendo estrategias educativas que no indaguen desde una perspectiva histórica a los mapas, más que contribuir al análisis crítico de los procesos de constitución de los Estados-nación se asiste a reproducir una imagen cristalizada, atemporal y esencialista del territorio nacional presente en muchos relatos tendenciosos y victimizantes sobre los que se legitiman algunos reclamos territoriales actuales. 


\section{Referencias}

ANDERSON, Benedict. Imagined communities: reflections on the origin and spread of nationalism. London: Verso, 1983.

ARTEAGA, Belinda; CAMARGO, Siddharta. Educación histórica: una propuesta para el desarrollo del pensamiento histórico en el plan de estudios de 2012 para la formación de maestros de Educación Básica. Revista Tempo e Argumento, Florianópolis, v. 6, n. 13, p. 110 139, set./dez., 2014.

BARTON, Keith. Research on students' ideas about history. En: LEVSTIK, Linda; THYSON Cinthia (Eds.). Handbook of research on social studies education. New York, NY: Routledge, 2008, p. 239-258.

BARTON, Keith; LEVSTIK, Linda. History. En: ARTHUR, James; DAVIES, Ian; HAN, Carole (Eds.). Handbook of education for citizenship and democracy. London: Sage, 2008, p. 355-366.

BILLIG, Michael. Nacionalismo banal. Salamanca: Capitán Swing, 1995.

CAIRO CAROU, Heriberto. Jano desorientado: identidades político-territoriales en América Latina. Leviatán, v. 79, p. 107-119, 2000.

CARRETERO, Mario. Constructing patriotism: teching of the history and historcal memory in globalized world. Charlotte, NC: Information Age Publishing, 2011.

CARRETERO, Mario. Representación y aprendizaje de narrativas históricas. En: CARRETERO, Mario; CASTORINA, José Antonio (Coords.). Desarrollo cognitivo y educación [II]: procesos del conocimiento y contenidos específicos. Buenos Aires: Paidós, 2012, p. 221-242.

CARRETERO, Mario; LEE, Peter. Learning history. En: SAWYER, Robert Keith (Ed.), Handbook of learning sciences. 2. ed. Cambridge, UK: Cambridge University Press, 2014

CAVALERI, Paulo. La restauración del virreinato: orígenes del nacionalismo territorial argentino. Bernal: Universidad Nacional de Quilmes, 2004.

CHIARAMONTE, José Carlos. Nación y estado en iberoamérica: el Lenguaje político en tiempos de las independencias. Buenos Aires: Sudamericana, 2004.

CRAMPTON, Jeremy. Maps as social constructions: power, communication and visualization. Progress in Human Geography, v. 25, n. 2, p. 235-252, 2001. 
DAVIS, Ozro. Jr. Graphic illustrations with geographic texts: on exploring a vast unknown. Peabody Journal of Education, v. 46, n. 1, p. 39-44, 1968.

DEL CASTILLO, Lina. Educating the Nation. En: DYM, Jordana; OFFEN, Karl (Eds.). Mapping Latin America: a cartographic reader. Chicago: The University of Chicago Press, 2011, p. 193-197.

DOMINGUEZ, Jesús. Pensamiento histórico y evaluación de competencias. Barcelona: Editorial Grao, 2015.

EDNEY, Matthew. Mapping and empire: the geographical construction of British India 1765-1843. Chicago: University of Chicago Press, 1997.

ENTIN, Gabriel. Enigmas y dilemas de la independencia. En: ENTIN, Gabriel et al. (Eds.) Crear la independencia: historia de un problema argentino. Buenos Aires: Capital Intelectual, 2016, p. 9-26.

FOSTER, Stuart. Re-thinking historical textbooks in a globalised world. En: CARRETERO, Mario; ASENCIO, Mikel; RODRÍGUEZ-MONEO, Maria (Eds.). History education and the construction of national identities. Charlotte, NC: Information Age Publishing, 2012, p. 4962.

FOSTER, Stuart; CRAWFORD, Keith. What shall we tell the children? International perspectives on school history textbooks. Greenwich, CT: Information Age Publishing, 2006.

GARAVAGLIA, Juan Carlos. La disputa por la construcción nacional Argentina: Buenos Aires, la Confederación y las provincias (1850-1865). Buenos Aires: Prometeo, 2015.

GÓMEZ CARRASCO, Cósme Jesús. Pensamiento histórico y contenidos disciplinares en los libros de texto: un análisis exploratorio de la Edad Moderna en $2^{\circ}$ de la ESO. Ensayos, Revista de la Facultad de Educación de Albacete, v. 29, n. 1, p. 131-158, 2014.

GÓMEZ CARRASCO, Cosme Jesús; ORTUÑO, Jorge; MOLINA, Sebastián. Aprender a pensar históricamente. Retos para la historia en el siglo XXI. Revista Tempo e Argumento, Florianópolis, v. 6, n.11, p. 05-27, jan./abr., 2014.

GRAMSCI, Antonio. Selections from the prison notebooks. En: HOARE, Quentin; NOWELL-SMITH, Geoffrey (Eds.). Selections from the prison notebooks of Antonio Gramsci. New York: International Publisher, 1971. 
GRATY, Marbais du. (Cartographer). Carte de la confederation Argentine. 1958. Retrieved from: <https://imagenes.educ.ar/repositorio/imagen/ver?image_id=55cf6619-ccd6-406983c0-d621231bf332>. Acesso em 20/09/2017.

HARLEY, Brian. La nueva naturaleza de los mapas: ensayos sobre la historia de la cartografía. México D.F.: Fondo de Cultura Económica, 2005.

HERB, G. Henrik. Under the map of Germany: nationalism and propaganda 1918-1945. New York: Routledge, 1997.

HERZOG, Tamar. Historical rights to land: how Latin American States Made the past normative and what happened to history and historical education as a result. En: CARRETERO, Mario; BERGER, Stephan; GREVER, María (Eds.). Palgrave handbook of research in historical culture and education. New York, NY: Palgrave, 2017, p. 91-108.

HOBSBAWN, Eric. Naciones y nacionalismos desde 1780. Barcelona: Crítica, 1998.

HOBSBAWN, Eric. La era de la revolución (1789-1848), la era del capital (1848-1875), la era del imperio (1875-1914). Buenos Aires: Crítica, 2012.

HOLLMAN, Verónica; LOIS, Carla. Geo-grafías: imágenes e instrucción visual en la geografía visual. Buenos Aires: Paidós, 2015.

KAMUSELLA, Tomasz. School history atlases an instruments of nation-state making and maintenance: a remark on the invisibility of ideology in popular education. Journal of Educational Media, Memory, and Society, v. 2, n. 1, p. 113-138, 2010.

KANTOR, Iris. Prólogo. Los mapas y las cosas: mediaciones entre lo visible y lo invosible. En: LOIS, Carla (Ed.), Mapas para la nación: episodios de la historia de la cartografía Argentina. Buenos Aires: Editorial Biblos, 2014, p. 11-16.

KAPLAN, David; HERB, Guntram Henrik. How geography shapes national identities? National Identities, v. 13, n. 4, p. 349-360, 2011.

KITCHIN, Rob; DODGE, Martín. Rethinking Maps. Progress in Human Geography, v. 31, n. 3, p. 331-344, 2007.

KOSONEN, Katariina. Making maps and mental images: finnish press cartography in nation-building. National Identities, v. 10, n. 1, p. 21-47, 2008.

LEE, Peter. Putting principles intro practice: understanding history. En: DONOVAN, Suzanne; BRANDSFORD, John (Eds.). How students learn: history in the classroom. Washington: National Academies Press, 2005, p. 31-77. 
LEUENBERGER, Cristine; SCHNELL, Izhak. The politics of maps: constructing national territories in Israel. Social Studies of Science, v. 40, n. 6, p. 803-842, 2010.

LÉVESQUE, Stephan. Thinking historically: educating students for the 21th century. Toronto: University of Toronto Press, 2008.

LÉVESQUE, Stephan. What it means to think historically. En: CLARK, Penney (Ed.). New possibilities for the past: shaping history education in Canada. Vancouver: UBC Press, 2011, p. 115-135.

LOIS, Carla. La patria es una e indivisible. Terra Brasilis (Nova Série) [on line], n.1. 2012. Retrieved from: <http://terrabrasilis.revues.org/138>. doi:10.4000/terrabrasilis.138 Acessso em: 20/09/2017.

LOIS, Carla. Mapas para la nación: episodios en la historia de la cartografía Argentina. Buenos Aires: Editorial Biblos, 2014.

LÓPEZ FACAL, Ramón. Pensar históricamente. Íber, Didáctica de las Ciencias Sociales, Geografía e Historia, n. 24, p. 46-57, 2000.

MOUSSY, Martin de. (Cartographer). Atlas de la confederation Argentine. 1865. Retrieved from: <https://imagenes.educ.ar/repositorio/imagen/ver?image_id=42d 48c70078d-4cc7-b34b-f7ff2of6ad56>. Acesso em: 20/09/2017.

NAKOU, Irene; BARCA, Isabel. Contemporary public debates over history education. Charlotte, NC: Information Age Publishing, 2010.

NOGUÉ, Joan. Nacionalismo y territorio. Lleida: Editorial Milenio, 1998.

OFFEN, Karl; DYM, Jordana. Introduction. En: DYM, Jordana; OFFEN, Karl (Eds.), Mapping Latin America: a cartographic reader. Chicago: The University of Chicago Press, 2011, p. 118.

ORRIDGE, Andrew; WILLIAMS, Colin. Autonomist nationalism: a theoretical framework for spatial variations and its Genesis and Development. Political Geography Quarterly, v. 1, p. 19-39, 1982.

OSZLAK, Omar. La formación del Estado Argentino: orden, progreso y organización nacional. Buenos Aires: Ariel, 2012.

PAGÈS BLANCH, Joan; SANTISTEBAN FERNÁNDEZ, Antoni. La enseñanza y el aprendizaje del tiempo histórico en la educación primaria. Cadernos Cedes, Campinas, v. 30, n, 82, p. 281-309, set./dez., 2010. 
PARELLADA, Cristian. Mapas históricos y libros de texto en América Latina. Iber: Didáctica de las Ciencias Sociales, Geografía e Historia, n. 85, p. 28-33, 2016.

PECK, Carla; SEIXAS, Peter. Benchmarks of historical thinking: first steps. Canadian Journal of Education, v. 31, n. 4, p. 1015-1038, 2008.

PÉREZ, Mariana; et al. Historia de la Argentina. Buenos Aires: Kapelusz, 2013.

QUINTERO, Silvina. El País que nos contaron: la visión de la Argentina en los manuales de geografía (1950-1997). Entrepasados, v. 16, p. 135-154, 1999.

RADCLIFE, Sara. Frontiers and popular nationhood: geographies of identity in the 1995 Ecuador-Peru border dispute. Political Geography, v. 17, n. 3, 273-293, 1998.

RAMASWAMY, Sumathi. Maps and mother goddesses in modern India. Imago Mundi, v. 53, p.97-114, 2001.

ROBINSON, Arthur. The look of maps: an examination of cartographic design. Madiso, WI: University of Wisconsin Press, 1952.

ROMERO, José Luis. La Argentina en la escuela: la idea de nación en los textos escolares. Buenos Aires: Siglo XXI, 2004.

SEIXAS, Peter; MORTON, Tim. The big six: historical thinking concepts. Toronto: Nelson Education, 2013.

SOUZA, Rosa Fátima de. História da cultura material escolar: um balanço inicial. En: BENCOSTTA, Marcus Levy Albino (Org.). Culturas escolares, saberes e práticas educativas: itinerários históricos. São Paulo: Cortez, 2007, p. 163-189.

VALLS, Rafael. La enseñanza de la historia y textos escolares. Buenos Aires, Zorzal, 2008.

VANSLEDRIGHT, Bruce. Narratives of nation-state, historical knowledge, and school history education. Review of Research in Education, v. 32, n. 1, p. 109-146, 2008.

VANSLEDRIGHT, Bruce. Assessing historical thinking and understanding: Innovate designs for new standards. New York: Routledge, 2014.

VANSLEDRIGHT, Bruce; LIMÓN, Margarita. Learning and teaching in social studies: Cognitive research on history and geography. En: ALEXANDER, Patricia; WINNE, Philip (Eds.). The Handbook of Educational Psychology. 2. ed. Mahweh, NJ: Lawrence Erlbaum Associates, 2006, p. 545-570. 
WINEBURG, Sam. Historical thinking and other unnaturals acts:
teaching the past. Philadelphia: Temple University Press, 2001.

WOOD, Denis (2010). Rethinking the power of maps. New York: The Guilford Press.

Recebido em 14/03/2017

Aprovado em 21/08/2017

Universidade do Estado de Santa Catarina - UDESC

Programa de Pós-Graduação em História - PPGH

Revista Tempo e Argumento

Volume 09 - Número 21 - Ano 2017

tempoeargumento@gmail.com 